\title{
Lester Embree POR LAS CUeStAS De Segovia
}

\author{
LESTER EMBREE UP AND DOWN THE SEgOVIAN SLOPES
}

Agustín Serrano de Haro Instituto de Filosofia Consejo Superior de Investigaciones Científicas (CSIC), Madrid agustin.serrano@cchs.csic.es

Lester Embree visitó asiduamente España por motivos científicos y académicos pero también por razones personales y de ocio, y dado que frecuentaba asimismo la América hispana no entendía nada mal el castellano, que se permitía chapurrear con gracia. Mis recuerdos más vivos de su figura y su persona remiten en particular a los Congresos que la SEFE organizó en Segovia en los años 2009 y 2011. El primer encuentro fue el IX Congreso Internacional de Fenomenología y Segundas Jornadas Ibéricas de Fenomenología, en el cual él intervino en la sesión de clausura con una ponencia sobre la interdisciplinariedad en fenomenología. Recuerdo que se centró ante todo en fenomenología de la enfermería, aportando una notable documentación sobre la presencia de esta orientación en los EE.UU. y sobre sus bases conceptuales; la ensalzó grandemente como un modelo de práctica fenomenológica innovadora y fecunda, ligada al mundo de la vida y que evitaba los tecnicismos estériles de la mera discusión académica.

El segundo encuentro segoviano fue el IV Congreso OPO, y en él Lester tomó la palabra más bien en el solemne acto de inauguración, en su calidad de fundador de la Organization of Phenomenological Organizations. Pero en el desarrollo del Congreso tuvo además una intervención dedicada a Dorion Cairns, su maestro en fenomenología en la New School for Social Research en los años sesenta, que representaba un nexo vivo de relación con la gran época creadora de la 
fenomenología en Friburgo. Creo que él debía de sentirse integrado en esa línea de continuidad Husserl-Fink-Cairns, y de hecho, pese a sus alegatos antiacademicistas, contribuyó notablemente a la edición de trabajos inéditos del propio Cairns; por ejemplo, los muy interesantes ensayos acerca de sensibilidad intracorporal. Alguna vez me contó él mismo la anécdota de que Hannah Arendt había formado parte del tribunal que juzgó su, creo, tesis doctoral en la New School, y que en esa ocasión fue él quien se vio interpelado por ella sobre el interés que a esas alturas del siglo XX podía tener la investigación académica acerca de Hume. En todo caso, y por no perder el hilo de mis palabras, el Congreso OPO en Segovia debía mucho a la persona de Lester Embree: por la designación, que él defendió con todo entusiasmo en el anterior encuentro de Hong-Kong en 2008 (también sin demasiada oposición, todo sea dicho); por la contribución financiera del CARP -Centre for Advanced Research in Phenomenology- que entonces él presidía; e incluso por los ánimos e ideas que trasmitió durante la preparación. Debió de pensar que tanto apoyo le era pagado malamente, en forma de empinadas cuestas, suelos empedrados y recorridos sinuosos de la ciudad medieval, por los que su humanidad ya entrada en años tenía a veces que rezagarse entre risas y buen humor. Pero tampoco aquí desaprovechó la ocasión de invitar a sus amigos y amigas, y él tendía a considerar tales a quienesquiera se dedicaran a la fenomenología o, al menos, a cuantos empezaban en ella y a cuantos él pudiera tratar como jóvenes en un sentido muy amplio.

Es conocida la enorme labor de Embree en la internacionalización y globalización de la fenomenología, que para él pasaba de manera fundamental por poner en relación, y en redes lo menos jerarquizadas posibles, a personas, sociedades y grupos. Debía ser una trama amplísima pero con rostros humanos por doquier. Si le desagradaba el academicismo, por más que él tuviera conocimientos académicos sólidos, también se manifestaba con toda rotundidad contra la amenaza del "monolingüismo fenomenológico" - creo que lo llamaba así- que en el presente representaba el inglés, su lengua. Le gustaba contar los lugares inverosímiles en que habían aparecido grupos de fenomenólogos, a veces grupos de dos o de tres personas en enclaves remotos, y la multitud de lenguas en que se comunicaban y la posibilidad de interconexiones regionales que él concebía; por supuesto, también tenía siempre en la cabeza programas de traducciones mutuas y de obras colectivas sin ninguna lengua oficial. $Y$ en todo 
ello no era un soñador, sino mucho más un organizador. Yo tuve ocasión asimismo de coincidir con él en una Conferencia Euromediterránea de Fenomenología y Hermenéutica que se celebró en Nápoles en 2007, bajo los auspicios de Domenico Jervollino. El encuentro dedicado a tradiciones y traducciones tenía por propósito de fondo el diálogo intercultural entre las dos orillas del Mediterráneo, y asumía que fenomenología y hermenéutica, como filosofías sin una visión preconcebida del mundo, encerraban a tal respecto posibilidades que merecían activarse en contextos políticos difíciles. Asistieron delegados franceses, italianos, portugueses, españoles, egipcios, turcos, tunecinos, etc., y el norteamericano Lester dio allí buenas muestras de su saber hacer en las negociaciones, no siempre fáciles, que fijaban los principios organizativos. Disfrutamos de la belleza increíble de Nápoles, pero no he olvidado que a alguna sesión fuera del casco urbano tuvimos que desplazarnos en microbuses escolares que, por más detalles, parecían proceder de la enseñanza primaria, y que suscitaron las bromas de Lester y las risas de todos por si él necesitaba tres o cuatro de aquellos mini-asientos para acomodarse; la prueba fue más dura que las cuestas de la ciudad castellana.

Al recordar ahora a Lester Embree, me resulta evidente que su gran contribución al conocimiento mutuo entre los fenomenólogos y fenomenólogas y a la cooperación generalizada y organizada no puede separarse de su forma afable de ser y de estar, de su campechanía y del contento con que vivió la dedicación personal y compartida a la fenomenología. En esta alegría se deja reconocer algo del talante de una filosofía que, es verdad, nunca ha calumniado a la vida. 